University of Windsor

Scholarship at UWindsor

1991

\title{
Group work as interventive modality with the older depressed client: A meta-analytic review
}

Kevin M. Gorey

University of Windsor

Arthur G. Cryns

University at Buffalo

Follow this and additional works at: https://scholar.uwindsor.ca/socialworkpub

Part of the Psychiatry and Psychology Commons, Psychology Commons, and the Social Work Commons

\section{Recommended Citation}

Gorey, Kevin M. and Cryns, Arthur G.. (1991). Group work as interventive modality with the older depressed client: A meta-analytic review. Journal of Gerontological Social Work, 16 (1/2), 137-157. https://scholar.uwindsor.ca/socialworkpub/21

This Article is brought to you for free and open access by the School of Social Work at Scholarship at UWindsor. It has been accepted for inclusion in Social Work Publications by an authorized administrator of Scholarship at UWindsor. For more information, please contact scholarship@uwindsor.ca. 


\title{
Group Work as Interventive Modality with the Older Depressed Client: A Meta-analytic Review
}

\author{
Kevin M. Gorey, MSW \\ Arthur G. Cryns, PhD
}

\begin{abstract}
This review analyzes a total of 19 empirical studies dealing with the effectiveness of group work intervention with depressed older clients (65 years and older). Multiple analyses of all outcome data reported allowed for the following summative, empirically derived inferences: (1) overall, group work was found to account for $42 \%$ positive change in client affective states; however, most of this improvement ( $87 \%$ ) appears to be attributable to nonspecific interventive variables, i.e., factors outside the control and intent of the group worker; (2) group work is optimally effective for clients who live alone and are moderately to severely depressed; (3) client age is no factor in group work effectiveness; and (4) the most effective format is constituted by small client groups and interventions of short duration.
\end{abstract}

Depression appears to be a major mental health problem among the elderly $(65+)$. Although sound epidemiological data are lacking, prevalence estimates range from $5-15 \%$ for community-residing elders (Charatan, 1985; Lehmann, 1982; Perse, Howell, \& Jefferson, 1986) to $36 \%$ for their institutionalized counterparts (Ruskin, 1985). The explanation usually given for these rather high

Kevin M. Gorey is Asscciate Director of Research, Multidisciplinary Center for the Study of Aging and Assistant Professor, School of Social Work, State University of New York at Buffalo, Diefendorf Annex-Room 19, Buffalo, NY 14214. Arthur G. Cryns is Director, Multidisciplinary Center for the Study of Aging, and Professor, School of Social Work, SUNY/AB.

Journal of Gerontological Social Work, Vol. 16(1/2) 1991

(1) 1991 by The Haworth Press, Inc. All rights reserved. 
figures is that, with increasing age, the number and intensity of biopsychosocial stressors that may lead to depression are likely to increase as well (Perse et al., 1986). Thus, the question of whether group work is an effective interventive modality with this client population is an important one.

The research literature is replete with descriptions of the benefits of group work. However, they are mostly clinical and qualitative in nature. As only a limited number of controlled studies have been undertaken in this particular domain of inquiry (Burnside, 1970), much of the published empirical research on group work with depressed elderly has to be characterized as lacking in methodological rigor. This paper will attempt to provide a synthesis of what is really known in this field and what its empirical data base is, thus allowing for the development of more focused hypotheses and research methodologies for future evaluative studies. Newly developed methods for a quantitative review of accumulated data bases are now available and are generically known as meta-analytic procedures (Becker, 1987; Cooper, 1984; Cooper \& Rosenthal, 1980; Glass, McGaw \& Smith, 1981; Hedges, 1984; Rosenthal, 1984; Wolf, 1986).

The theoretical underpinnings of group work with the elderly are mostly extrapolations of existing work with the young and generally deal with the comparative efficacy of traditional psychodynamic (PD) versus cognitive-behavioral (CB) methods of depression treatment (Lehmann, 1982; Perse et al., 1986; Settin, 1982). Within this framework, numerous client, interventive and contextual variables have been assumed to moderate interventive efficacy: age, health status, endogenous/exogenous depression type, chronicity (Burnside, 1970; Gallagher \& Thompson, 1983; Mintz, Steuer \& Jarvick, 1981; Murphy, 1985; Soreff, 1985); group leadership-client numbers and sex, practice paradigm (Linden, 1954; Linsk, Howe, \& Pinkston, 1975); social setting, live alone/cohabit and community/ institutional residence of clients (Linsk et al., 1975; Murphy, 1985; Petty, Moeller, \& Campbell, 1976; Soreff, 1985). Given the diversity of perspectives, individual outcomes provide little meaningful information about what works with whom, where, how and when.

Efforts to extract from this diversity of information salient and clinically useful information are further confounded by numerous 
methodological inconsistencies across studies as well as by design problems, such as the lack of specific operational definition of terms, bias in client selection, concurrent medical interventions and selective client attrition (Mintz et al., 1981). The use of nonequivalent control groups and the belief that the problems of the elderly are intractable may also contribute to the relative ambiguity of outcomes in this particular domain of research (Ingersoll \& Silverman, 1978; Linden, 1955; Settin, 1982).

Traditional reviews of group work effectiveness are provided by Burnside (1970), Hartford (1980), and Mayadas and Hink (1974). Sorting through large volumes of research literature, they render an important service to the clinician. However, their outcomes are generally not replicable in a systematic manner and, lacking empirical criteria, they demonstrate that numerous potential confounds impinge upon the validity of the results reported. Quantitative methods are clearly indicated if one is to gain an uncomplicated view of what is really known in this field. Utilizing empirically based meta-analytic techniques, this study will endeavor to answer the following questions. What is the average effect of group work upon the affective state of depressed older persons? Is this effect statistically/clinically significant? What are the comparative effects of various group work practice paradigms? Are these effects significantly greater than those produced by nonspecific interventive factors (attention and/or activity)? Finally, how do various client, interventive, contextual and study characteristics moderate the observed mean interventive effect?

\section{METHOD}

An initial group of studies, potentially relevant to the question of group work effect upon the affective state of older persons was retrieved through computer searches of data bases for Social Work and Psychological Abstracts, Index Medicus, and Dissertation Abstracts International for the time period 1967-1988. Focusing primarily upon external validity at this entry point, a maximally broad keyword scheme was employed. Computer searches were then augmented with a bibliographic review of retrieved manuscripts and with manual searches of the Index to Social Sciences \& Humanities 
Proceedings, Directory of Published Proceedings/Series SSH and Human Services Abstracts. One hundred and twenty-eight manuscripts were so retrieved, of which 66 met the population, constructual and relational demands of the central review question; by primary author's professional affiliation they broke down as follows: social work-18, psychology/psychiatry-39 and nursing-9. Review internal validity was subsequently addressed by application of the criterion that primary study outcomes be in a form amenable to quantitative effect size (ES) calculation, generally meaning that the design used in the study allowed for the collection of inferential rather than merely descriptive data. The studies satisfying the latter criterion numbered only 19 , with none of those coming from social work, 18 from psychology/psychiatry and 1 from nursing. They are cited in 'References (special section)' and provide the data base for this meta-analysis.

In this review, the central datum of analysis is constituted by the outcomes obtained in each of the 19 studies included in this metaanalysis. They were subjected to the following sequence of analytic procedures. First, the primary study outcomes were converted to Cohen's $d$-indices (1977). The latter index constitutes a measure of ES yielding a difference score between two group means expressed in terms of their average standard deviation. It can be computed for both between-group (experimental/comparison) and within group differences (pre/post tests). It has been noted that the methodological rigor of the primary studies was generally low, providing little assurance that the intervention and comparison groups used had true pretest equivalence (see Table 2). Consequently, review control was employed by means of an across-study $t$-test (ratio data) or Wilcoxon matched-pairs signed-ranks (ordinal data) comparison of intervention and control groups on all reported demographic and clinical variables. Subsequently, the combined probability of any interventive effect was calculated by means of adding $t s$ (Winer, 1971), $z$ s and $z$ s weighted for sample size (Rosenthal, 1978). The resistance of these outcomes to publication bias, i.e., their being the product of a selective sampling procedure, was ascertained through the Rosenthal method of comparing calculated and criterion failsafe Ns (Rosenthal, 1979). Furthermore, in an effort to sort out the relative variance in interventive effect effects accounted for by 
(a) specific, (b) nonspecific and (c) extraneous or confounding factors, weighted average (unbiased) $d$ analysis was carried out by means of a procedure developed by Hedges (1982). "Specific" effects are understood to be all actually observed and intended intervention effects, while "non-specific" ones are all others that accrue to a client as a result of being an object of intervention (e.g., getting more attention, being a member of a social group).

Finally, homogeneity of ES analysis (Rosenthal \& Rubin, 1982a) was performed the outcome of which would determine the necessity of moderator effect analyses. This procedure establishes whether the various ESs obtained cluster closely together (homogeneity) or are sufficiently dispersed (heterogeneity) to warrant such moderator effect analysis. Having established the latter, an exhaustive codification was undertaken of all client, interventive, contextual and design characteristics (see Table 1), this for purposes of a full empirical exploration of their moderating effects. Furthermore, as the differential effect of paradigmal orientation was assumed to be of particular interest to the clinician, the across-study pre-test group equivalence was tested prior to the between-group comparison of psychodynamic versus cognitive-behavioral approaches to depression.

\section{RESULTS}

The major demographic/descriptive characteristics of the reviewed populations are shown in Table 2. As may be noted, the review client sample tends to reflect the general older population in terms of age and sex distributions, while it seems to overrepresent those who live alone or reside in institutional settings. In addition, it was found to have a higher educational attainment level and socioeconomic status than the general population of elders. It also should be noted that most primary studies carried such client attributes as being verbal, oriented and without OBS.

As for intervention paradigm, the studies analyzed show a bimodal distribution with $\mathrm{CB}$ and PD orientations accounting for $77.2 \%$ of all groups. Little more can be said of intervention specificity in that studies, which conceptually defined intervention as PD, generally did not operationalize the construct beyond an emphasis on 


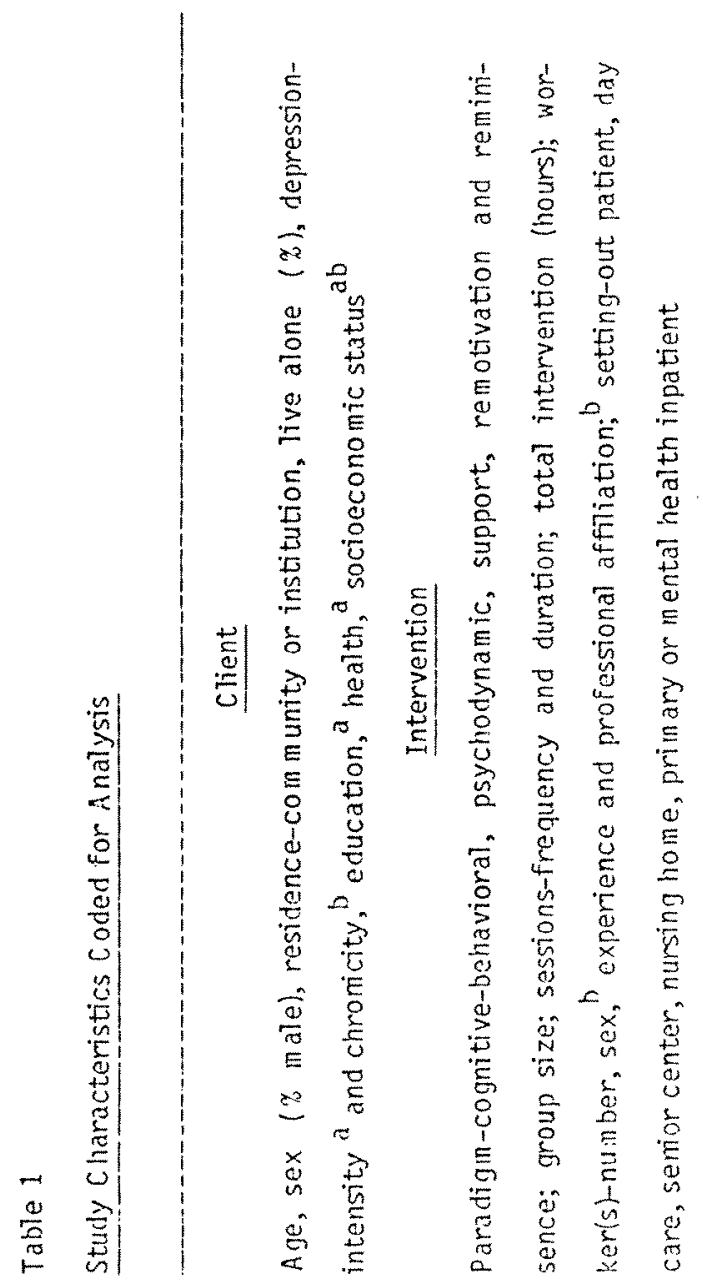




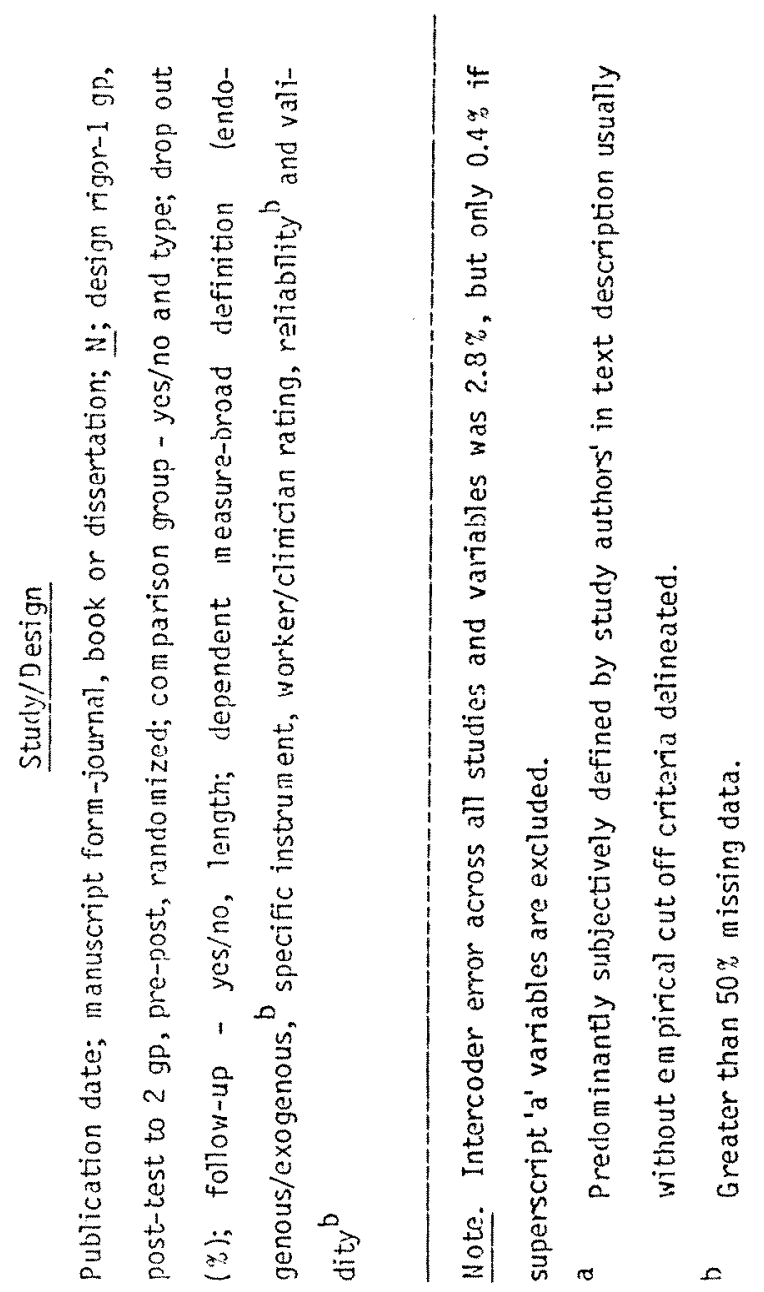




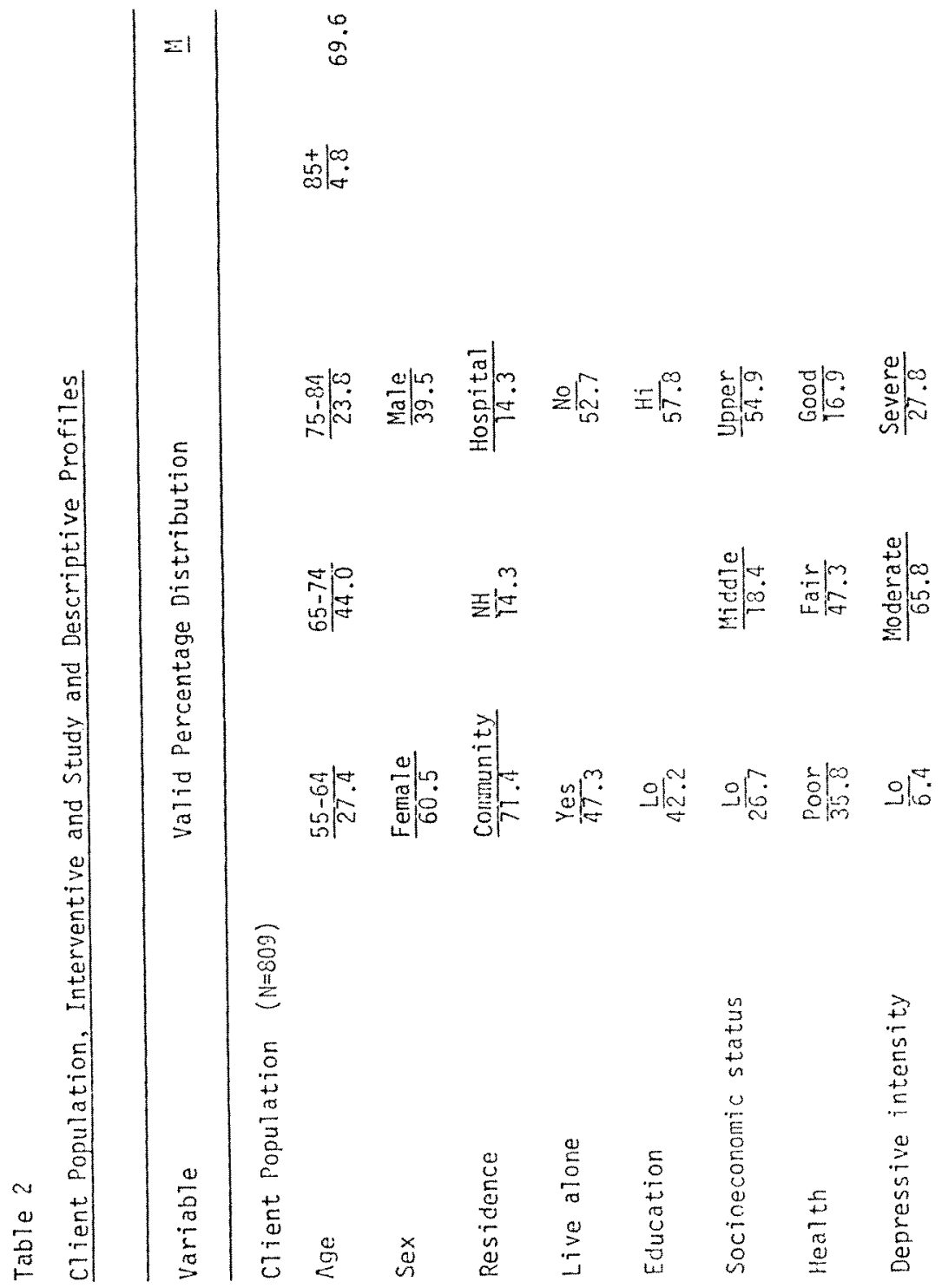


0
6

$\left.\frac{0}{1}\right|^{0}$

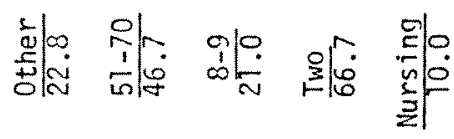

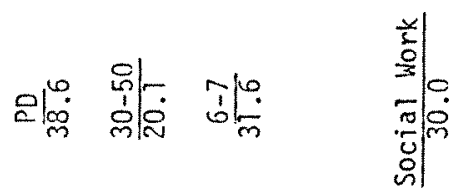

alo

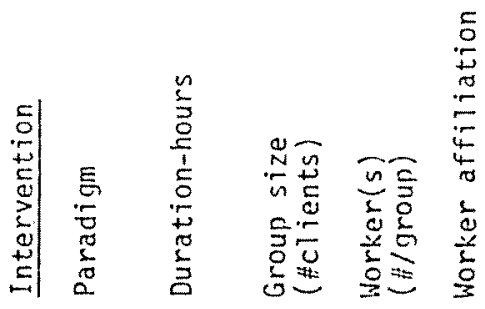




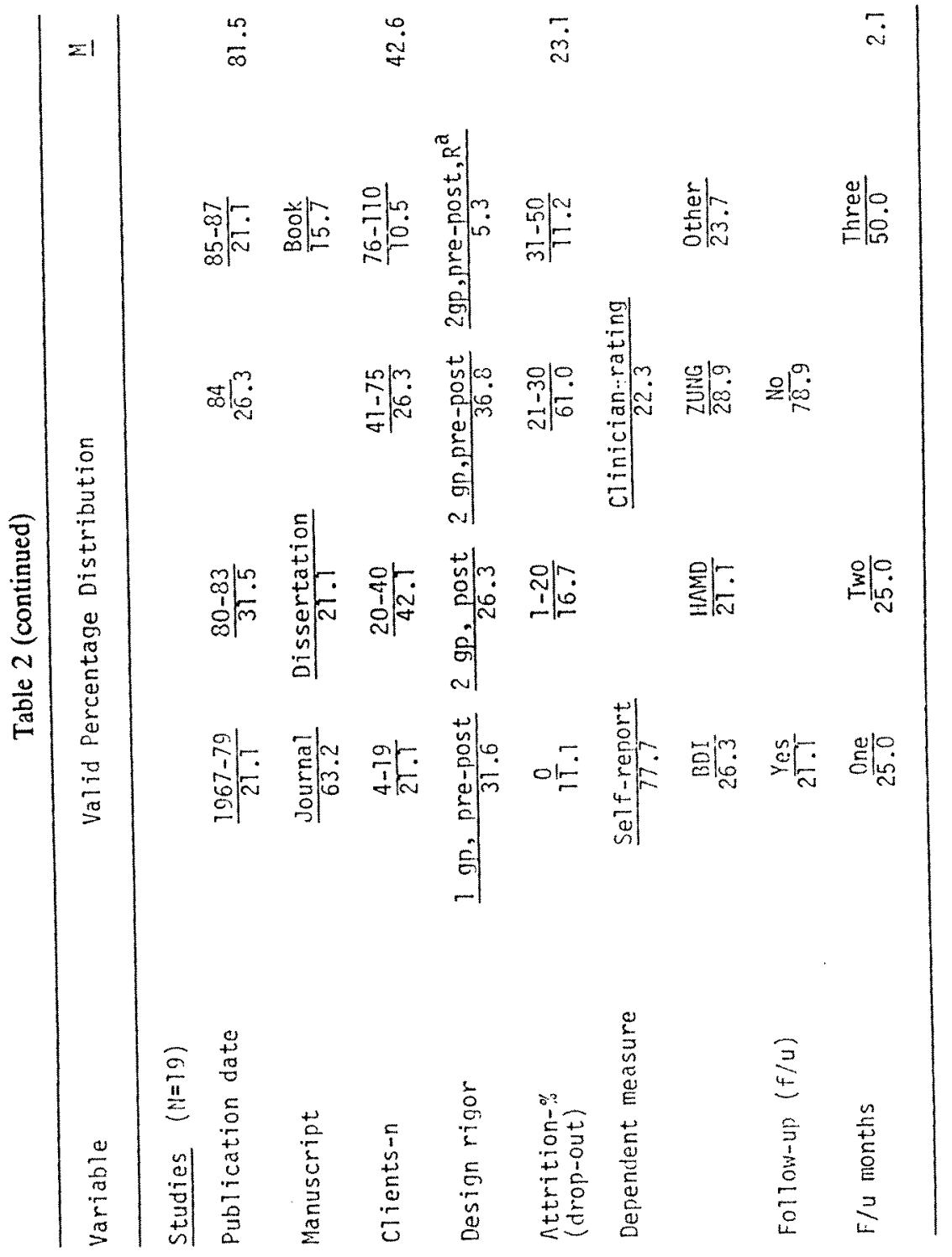


temporally distal events or insight. Similarly, those defined as CB did not operationalize beyond an emphasis on here-and-now behavior and/or cognitive sets. Group size varied widely from 4 to 14 members, with one-third employing a single group worker and twothirds being cofacilitated groups. Interestingly, whereas none of the primary authors were social workers, $30.0 \%$ of the actual group workers were. Additionally, interventions varied from brief to extended (10-160 hours). Finally, a review of the research designs used shows that the modal design employed was of the two group, nonrandomized (quasi-experimental) variety, with a relatively high rate of client attrition (23.1\%). Post-treatment follow-up was addressed by four studies only with the follow-up period generally being short $(M=2.1$ months).

\section{Main Effect}

Pre-test equivalence between the interventive and comparison groups on client age, sex, percent living alone, education, health and socioeconomic status, depression intensity and chronicity revealed only one significant difference: the percentage of comparison group clients living alone (59.1) was found to be nearly twothirds greater than that found for the interventive ones $(36.4)(t(10)=$ $5.52, p<.001$ (two-tailed)). Viewed in light of the groups' pre-test equivalence on depression indices, we do not expect the outcomes to be significantly confounded by this factor.

Before proceeding with a report on the combined probability and ES analyses, we shall examine the constructual domain(s) encompassed by the primary study dependent measures of depression. Table 2 shows that the Beck Depression Inventory (Beck \& Beamesderfer, 1974), Hamilton Depression (Hamilton, 1967) and Zung Self-Related Depression (Zung, 1965) scales accounted for more than three-quarters of the depressive measures utilized, with less than $25 \%$ represented by an array of other standardized and author defined measures. The convergence of the data upon one global review construct was supported by the fact that the one-way ANOVAs on ES by dependent measure groupings, as defined in Table 2, were found to be nonsignificant.

When probabilities were combined across studies through addi- 
tion of $t \mathrm{~s}, z \mathrm{~s}$ and weighted $z \mathrm{~s}$, outcomes of $z=4.63,3.94$ and 3.62 respectively were obtained, all significant at $p<.001$ (one-tailed). As for publication bias, the fail-safe $N$ at $p=.05$ was calculated to be 90 . This is a fairly large resistance number in that 90 studies with null results would have to exist to overcome the significance of the interventive effect found in this analysis. It falls just short of Rosenthal's suggested criterion value of five times the number of retrieved studies plus 10 , equalling 105 for this review. It seems however, that this large $N_{F S .05}$, in combination with the nonsignificance of a one-way ANOVA on ES by journal or book versus dissertations, $(\mathrm{F}(1,17)=0.04)$, suggests high resistance of the interventive effect to unpublished null results. In other words, the effects obtained in this analysis and their significance are real, i.e., they are not likely to be invalidated by different outcomes extant in nonpublished research.

Table 3 provides a display of $d$-index distribution by comparison group; a total of 44 outcomes are shown. The table represents a modification of a data presentation format suggested by Tukey (1977), i.e., the numbers 2 and 8 to the right of 0.8 , under column "Group," represent $d$-indexes of 0.82 and 0.88 respectively. In addition to means and standard deviations, the foot of the table shows unbiased ES $(d)$ estimates and Cohen's (1977) $U$, statistics. At first sight, unbiased ES analysis of interventive groups alone $\left(d=0.92\right.$ and $\left.U_{3}=82.2 \%\right)$ would lead us to infer a strong relationship between group intervention and change in affective state (improvement), with $82.2 \%$ of the postintervention clients scoring below the mean preintervention score on the dependent measures of depression. However, conversion of $d$ to the corresponding $r$-index and coefficient of determination $\left(r=.42\right.$ and $\left.r^{2}=.17\right)$, demonstrates that group intervention accounts for only $17 \%$ of the variance in affective state change. Yet, the group of older clients receiving such treatment for depression showed a full $42 \%$ amelioration of depressive morbidity (Rosenthal \& Rubin, 1982b). Turning to group work versus no treatment at all, we see that after controlling for extraneous influences, such as history, maturation and regression toward the mean, ES reduces to $d=0.68$. When converted to a direct morbidity indicator $(r=.32)$, the inference can be made that approximately $76 \%(.32 / .42)$ of the change in 


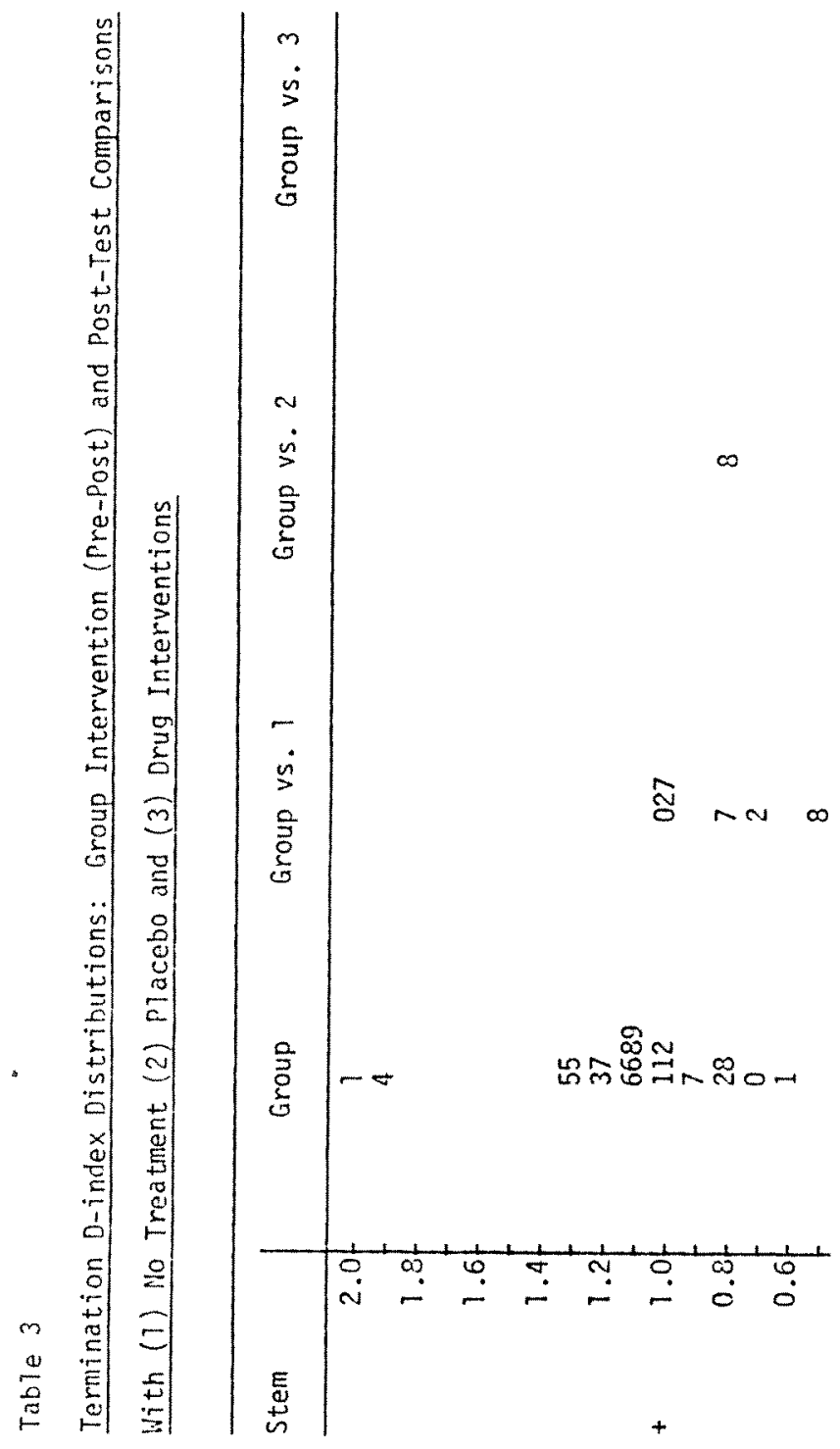




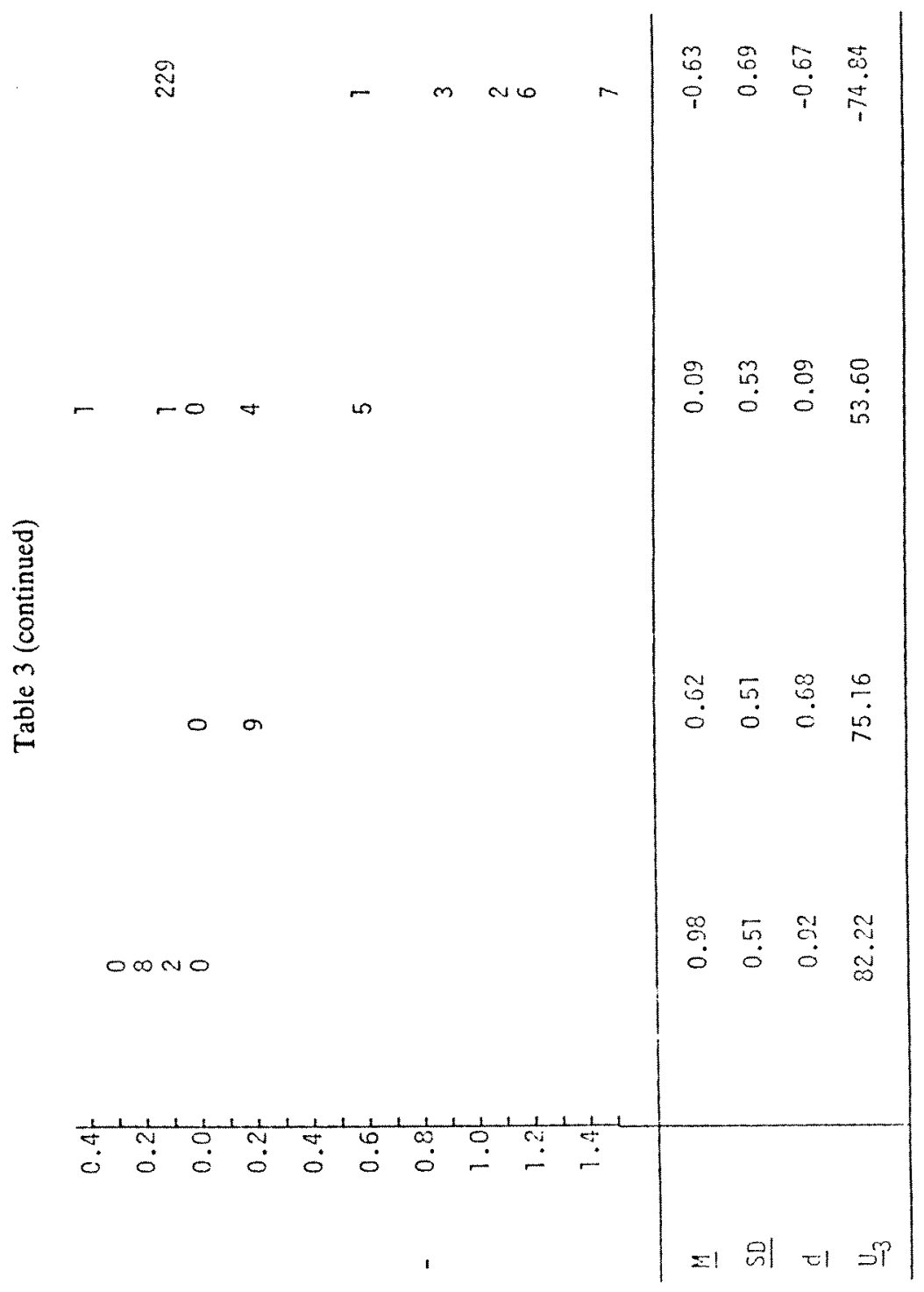


client depressive morbidity may be accounted for by interventive factors (specific and nonspecific) and $24 \%$ by extraneous, uncontrolled variables. Finally, the group work versus placebo comparisons $(d=0.09)$ are represented by a morbidity ES of $r=.04$. Thus, in terms of morbidity change, the interventive effect of group work breaks down to approximately $13 \%(.04 / .32)$ intervention specific effects and $87 \%(.28 / .32)$ nonspecific ones (attention and/or activity).

As indicated, only four studies attempted client post-treatment follow-up. This small sample did show a similar magnitude and pattern of ES as that seen immediately postinterventively with combined probabilities of $z=3.57, p<.001$; and $d=1.06\left(U_{3}=\right.$ 85.2). Total change in follow-up morbidity was accounted for mostly by interventive factors $(89 \%)$ and the remainder by extraneous ones $(11 \%)$. Of the interventive effects, $27 \%$ were specific and $72 \%$ were non-specific.

\section{Moderator Effects}

Analysis of ES homogeneity (chi-square $(18)=52.95, p<$ .001) showed a significantly large degree of heterogeneity in ES distribution to warrant further analyses of the moderating effects of client, interventive, contextual and design characteristics upon the relationship between group work and client depression. It is through such analysis that a better understanding is obtained of this complex inter-relationship that more focused hypotheses can be articulated in future primary research endeavors.

The study/design characteristics associated with ES all seem to be related to the issue of internal validity. First, publication date was found to be inversely related to $\operatorname{ES}(r=.52, p=.024$. This is probably a reflection of more recent studies being of greater methodological rigor. ES attenuated by two-thirds with design movement from lowest to highest level of rigor $(F(3,18)=9.90, p<$ $.001)$. A comparison of studies with client drop out ranges of 0 $15 \%$ versus those recording 16-50\% attrition produced ESs of $d=$ 1.26 and 0.31 , respectively. This outcome provides support for the notion that subject attrition was selective: persons terminating early are apt to be those who may benefit most from group intervention. 
In an attempt to control the confounding influence of differences in internal validity among the primary studies, the moderating effects of client, intervention and contextual factors were explored while design rigor was held constant (one group, pre-post). Studies in which more than $25 \%$ of the clients lived alone produced ES outcomes nearly double those below this criterion, $d=1.42$ and 0.84 , respectively $(F(1,10)=5.50), p=.041)$. Moreover, groups in which depression was narratively defined as mild $(d=$ $0.14)$, moderate $(0.94)$ and severe $(1.37)$ were each significantly different from the others $(F(2,18)=7.07, p=.005)$ (Duncan $p=.05)$. Taken together, these outcomes seem to demonstrate that severity of depression, and social isolation are reliable predictors, of the success of group intervention with this older client population.

Only one intervention characteristic (group size) significantly affected ES: small groups were found to be more successful than large ones $(<6$ clients, $d=1.38$ and $6-14, d=0.81 ; F(1,16)=6.49$, $p=.022$ ). Of equal clinical interest are those characteristics which did not influence interventive effect. ESs were not significantly different across paradigmal orientation; CB, PD or any other, (i.e., support, reminiscence or remotivation). The difference between brief and extended group work also proved non-significant. Finally, the generality of group work effect with this older client population is further supported by the fact that setting (community/institution) and basic client demographics (age and sex) were found not to moderate ES.

\section{Interaction Effects}

No primary study provided a true factorial design for the testing of interaction effects. To substitute for this deficit, an exploration was made of client or contextual by interventive interactions. Following up on one of the questions raised earlier, (i.e., the $\mathrm{CB} / \mathrm{PD}$ debate), this factor was entered with all coded client and contextual variables in a series of two-way ANOVAs on ES. None yielded significant interactions, hereby supporting the homogeneity of ES across major clinical orientations. A similar analysis was attempted, which used endogenous versus exogenous etiology of de- 
pression as the independent variable. However, due to missing data along this dimension, there was insufficient cell information for the testing of interaction effects.

Another point of interest is that of the relative effect of group and drug interventions. Five studies compared the effects of group work and drug therapy, but only one (Beutler et al., 1987) examined combinations of both modalities. Group/drug comparisons revealed the superiority of drug therapy for the study sample as a whole: $74.8 \%$ of the clients treated with drugs scored below the mean group work clients' depression score at post-test (see Table 3). The drugs administered were imipramine, doxepin (tricyclic antidepressants), and alprazolam (a benzodiazepine). ANOVAs on ES produced no significant differences between individual drugs or classes. Finally, the findings of Beutler et al. (1987) showed drug (alprazolam), cognitive group and combined intervention to be equally effective; in fact, the ES of the combination was somewhat less than either mode taken alone, although not significantly so.

\section{DISCUSSION}

A number of review outcomes may be particularly important for the clinical practitioner. First, the mean global effect of group work with older depressed clients seems to be both statistically and clinically significant with intervention accounting for a $32 \%$ positive change in client morbidity. Evidence also suggests that effectiveness may be maximized by providing services in a small group format and targeted to those who live alone and/or are moderately to severely depressed. Secondly, this interventive effect was found to be homogeneous across all older age cohorts, group work duration and clinical paradigms. The finding that the old-old $(75+)$ and the young-old (55-64) enjoyed similar interventive effects argues strongly against any selective application of treatment based on age. Thirdly, brevity of intervention would seem to be indicated for all as extended work does not seem to bring concomitant clinical gains. Finally, the issue of differences in psychodynamic versus cognitivebehavior of depression seems to be a moot point; such labels have little meaning when they are not accompanied by observable differences in treatment and practitioner behavior. 
This last point relates to a third, particularly interesting, outcome, i.e., that only $13 \%$ of client change was accounted for by intervention specific factors and $87 \%$ by nonspecific ones. It is clear that group participation works for this population, but what about it works seems to be unclear. Future care in testing method-specific hypotheses will aid in clarifying this issue. Finally, the lack of diagnostic specificity, observed in the studies reviewed, was found to have the effect of confounding the group work/drug therapy comparison. In general, drug therapy seems to be more effective. However, client individual differences along diagnostic lines (e.g., endogenous/exogenous and chronicity) and in the measurement of depressive factors (i.e., somatic, behavioral, cognitive and environmental) have so far been neglected; and adverse consequences of drugs, particularly long term ones, have not been examined. With a rather large demonstrated effect of group work and a voluminous literature on adverse drug effects in this population, group work alone probably provides the optimal long term interventive effect. However, further research through designs which handle the above mentioned confounds is clearly needed.

\section{REFERENCES}

Beck, A., \& Beamesderfer, A. (1974). Assessment of depression: The depression inventory. Modern Problems in Phamacopsychiatry, 7, 151-169.

Becker, B.J. (1987). Applying tests of combined significance in meta-analysis. Psychological Bulletin, 102, 164-171.

Burnside, I.M. (1970). Group work with the aged: Selected literature. Gerontologist, 10, 241-246.

Charatan, F.B. (1985). Depression and the elderly: Diagnosis and treatment. Psychiatric Annals, 15, 313-316.

Cohen, J. (1977). Statistical power analysis for the behavioral sciences (rev. ed.). New York: Academic Press.

Cooper, H.M. (1984). The integrative research review: A systematic approach. Beverly Hills, CA: Sage.

Cooper, H.M., \& Rosenthal, R. (1980). Statistical versus traditional procedures for summarizing research findings. Psychological Bulletin, 87, 442.449.

Gallagher, D.E., \& Thompson, L.W. (1983). Effectiveness of psychotherapy for both endogenous and nonendogeneous depression in older adult outpatients. Journal of Gerontology, 38, 707-712.

Glass, G.V., McGaw, B., \& Smith, M.L. (1981). Meta-analysis in social research. Beverly Hills, CA: Sage. 
Hamilton, M. (1967). Development of a rating scale for primary depressive illness. British Joumal of Social and Clinical Psychology, 6, 278-296.

Hartford, M.E. (1980). The use of group methods for work with the aged. In J.E. Birren \& R.B. Sloane (Eds.), Handbook of mental health and aging (pp. 806826). Englewood Cliffs, NJ: Prentice Hall.

Hedges, L.V. (1982). Estimation of effect size from a series of independent experiments. Psychological Bulletin, 92, 490-499.

Hedges, L.V. (1984). Advances in statistical methods for meta-analysis. In W.H. Yeaton \& P.M. Wortman (Eds.), Issues in data synthesis (pp. 25-43). Washington, DC: Jossey-Bass.

Ingersoll, B., \& Silverman, A. (1978). Comparative group psychotherapy for the aged. Gerontologist, 18, 201-206.

Lehmann, H.E. (1982). Affective disorders in the aged. Psychiatric Clinics of North America, 5, 27-44.

Linden, M.E. (1954). The significance of dual leadership in gerontologic group psychotherapy: Studies in gerontologic human relations III. International Journal of Group Psychotherapy, 4, 267-273.

Linden, M.E. (1955). Transference in gerontologic group psychotherapy: Studies in gerontologic human relations IV. International Joumal of Group Psychotherapy, 5, 61-79.

Linsk, N., Howe, M.W., \& Pinkston, E.M. (1975). Behavioral group work in a home for the aged. Social Work, 20, 454-463.

Mayadas, N.S., \& Hink, D.L. (1974). Group work with the aging: An issue for social work education. Gerontologist, 14, 440-445.

Mintz, J., Steuer, J., \& Jarvik, L. (1981). Psychotherapy with depressed elderly patients: Research considerations. Journal of Consulting and Clinical Psychology, 49, 542-548.

Murphy, E. (1985). General management of depression in late life. Journal of Affective Disorders, Supplement 1, S7-S10.

Perse, T., Howell, T., \& Jefferson, J.W. (1986). Depression in the chronically mentally ill elderly. In N.S. Abramson, J.K. Quam, \& M. Wasow (Eds.), The elderly and chronic mental illness: New directions for mental health services (pp. 15-32). San Francisco, CA: Josey-Bass.

Petty, B.J., Moeller, T.P., \& Campbell, R.Z. (1976). Support groups for elderly persons in the community. Gerontologist, 15, 522-528.

Rosenthal, R. (1978). Combining results of independent studies. Psychological Bulletin, 85, 185-193.

Rosenthal, R. (1979). The "file drawer problem" and tolerance for null results. Psychological Bulletin, 86, 638-641.

Rosenthal, R. (1984). Meta-analytic procedures for social research. Beverly Hills, CA: Sage.

Rosenthal, R. \& Rubin, D.B. (1982a). Comparing effect sizes of independent studies. Psychological Bulletin, 92, 500-504.

Rosenthal, R., \& Rubin, D.B. (1982b). A simple, general purpose display of 
magnitude of experimental effect. Journal of Educational Psychology, 74, 166-169.

Ruskin, P.E. (1985). Geropsychiatric consultation in a University hospital: A report on 67 referrals. American Joumal of Psychiatry, 142, 333-336.

Settin, J.M. (1982). Overcoming ageism in long-term care. Journal of Gerontological Nursing, 8, 565-567.

Soreff, S.M. (1985). Indications for home treatment. Psychiatric Clinics of North America, 8, 563-575.

Tukey, J.W. (1977). Exploratory data analysis. Boston, MA: Addison-Wesley. Winer, B.S. (1971). Statistical principals in experimental design, (2nd ed.). New York: McGraw-Hill.

Wolf, F.M. (1986). Meta-analysis: Quantitative methods in research synthesis. Beverly Hills, CA: Sage.

Zung, W. (1965). A self-rating depression scale. Archives of General Psychiatry, $12,63-70$.

\section{REFERENCES (SPECIAL SECTION)}

Beutler, L.E., Scogin, F., Kirkish, F., Schretlen, D., Corbishley, A., Hamblin, D., Meredith, K., Potter, R., Bamford, C.R., \& Levenson, A.I. (1987). Group cognitive therapy and alprazolam in the treatment of depression in older adults. Journal of Consulting and Clinical Psychology, 55, 550-556.

Dennis, H. (1984). Remotivation therapy. In I. Burnside (Ed.), Working with the elderly: Group process and techniques (pp. 187-197). Belmont, CA: Wadsworth.

Elder-Jucker, P.L. (1979). Effects of group therapy on self-esteem, social interaction, and depression of female residents in a home for the aged (Doctoral dissertation, Temple University, 1979). Dissertation Abstracts International, 39, 5514B.

Gallagher, D.E. (1979). Comparative effectiveness of group psychotherapies for reduction of depression in elderly outpatients (Doctoral dissertation, University of Southern California, 1979). Dissertation Abstracts International, 39, 5550B.

Hanssen, A.M., Meima, N.J., Buckspan, L.M., Henderson, B.E., Helbig, T.L., \& Zarit, S.H. (1978). Correlates of senior center participation. Gerontologist, 18, 193-199.

Hussian, R.A., \& Lawrence, P.S. (1981). Social reinforcement of activity and problem-solving training in the treatment of depressed institutionalized elderly patients. Cognitive Therapy and Research, 5, 57-69.

Jarvik, L.F., Mintz, J., Steuer, J., \& Gerner, R. (1982). Treating geriatric depression: A 26-week interim analysis. Joumal of the American Geriatrics Society, 30, 713-717.

Jarvik, L., Mintz, J., Steuer, J., Gerner, R., Aldrich, J., Hammen, C., Linde, S., McCarley, T., Motoike, P., \& Rosen, R. (1983). Comparison of tricyclic 
antidepressants and group psychotherapies in geriatric patients: An interim analysis. In P.J. Clayton \& J.E. Barrett (Eds.), Treatment of depression: Old controversies and new approaches (pp. 299-308). New York: Raven Press.

Matteson, M.A. (1984). Group reminiscing for the depressed institutionalized elderly. In I. Burnside (Ed.), Working with the elderly: Group process and techniques (pp. 287-297). Belmont, CA: Wadsworth.

Mintz, J., Mintz, L.I., \& Jarvik, L.F. (1985). Cognitive-behavioral therapy in geriatric depression: Reply to Riskind, Beck, and Steer. Joumal of Consulting and Clinical Psychology, 53, 946-947.

Moran, J.A., Walsh, C.P., \& Lax, R.L. (1984). Adult day care: Psychological practice and evaluation. Professional Psychology: Research and Practice, 15, $67-74$.

Nashef, A. (1980). The effects of group therapy on the affective states, social distance, interpersonal locus of control, life satisfaction, and ward behavior among the institutionalized aged (Doctoral dissertation, University of Toronto, 1980). Dissertation Abstracts International, 42, 384B.

Perrotta, P., \& Meacham, J.A. (1981-82). Can a reminiscing intervention alter depression and self-esteem? International Journal of Aging and Human Development, 14, 23-30.

Plotkin, D.A., Mintz, J., \& Jarvik, L.F. (1985). Subjective memory complaints in geriatric depression. American Joumal of Psychiatry, 142, 1103-1105.

Steuer, J.L., \& Hammen, C.L. (1983). Cognitive-behavioral group therapy for the depressed elderly: Issues and adaptations. Cognitive Therapy and Research, 7, 285-296.

Steuer, J.L., Mintz, J., Hammen, C.L., Hill, M.A., Jarvik, L.F., McCarley, T., Motoike, P., \& Rosen, R. (1984). Cognitive-behavioral and psychodynamic group therapy in treatment of geriatric depression. Joumal of Consulting and Clinical Psychology, 52, 180-189.

Sullivan, E.M., Coffey, J.F., \& Greenstein, R.A. (1987). Treatment outcome in a group geropsychiatry program for Veterans. Gerontologist, 27, 434-436.

Tutaj, G.A. (1975). The effectiveness of group counseling in alleviating depression among the aged (Doctoral dissertation, George Washington University, 1975). Dissertation Abstracts International, 36, 2653A.

Wolk, R.L., \& Goldfarb, A.I. (1967). The response to group psychotherapy of aged recent admissions compared with long-term mental hospital patients. American Joumal of Psychiatry, 123, 1251-1257. 
